\title{
Zinc Protoporphyrin
}

National Cancer Institute

\section{Source}

National Cancer Institute. Zinc Protoporphyrin. NCI Thesaurus. Code C123793.

An ionized form of the tetrazole protoporphryin IX that contains zinc in the metal ion binding pocket. Zinc protoporphyrin (ZPP) is formed in circulating red blood cells (RBC) either in the presence of lead or in the absence of sufficient iron, as both of these conditions inhibit the insertion of a ferrous ion into protoporphryin IX to form heme. Therefore, elevated levels of ZPP is associated with heme deficiency. Elevated RBC molar ratios of ZPP to heme are indicative of multiple pathologies including lead poisoning, iron deficiency, protoporphyria, and various types of anemia. 